\title{
Four-element MIMO Antenna System for UWB Applications
}

\author{
LingSheng YANG, Ming XU, Chun LI \\ Jiangsu Key Laboratory of Meteorological Observation and Information Processing, Research Center of Applied \\ Electromagnetics, NanJing University of Information Science \& Technology, China
}

ylsinchina@163.com, \{2450559561,945926942\}@qq.com

Submitted March 28, 2018 / Accepted December 10, 2018

\begin{abstract}
A four element multiple input multiple output (MIMO) antenna system for UWB applications is presented. The system consists of two identical slot dipoles and two identical planar monopoles. Polarization diversity between different kinds of antennas can realize lower coupling between antenna elements, and by using a couple of inverted L-shaped stubs and an inverted Z-shaped stub as decoupling structures, isolation can be further improved. For both simulation and measurement, higher than $17 d B$ isolation between antenna elements can be obtained through the whole UWB band $(3.1-10.6 \mathrm{GHz})$. The envelope correlation coefficient, antenna gain, efficiency and other performances are also provided.
\end{abstract}

\section{Keywords}

MIMO, UWB, polarization diversity, planar monopole, slot dipole

\section{Introduction}

Since the Federal Communications Commission (FCC) released the band of $3.1 \mathrm{GHz}$ to $10.6 \mathrm{GHz}$ for commercial communication applications in 2002, UWB technology has drawn a lot of interest in various applications [1]. However, when UWB systems work in multipath environments, serious signal fading can be caused due to the obligatory low radiation power [2]. MIMO technology has multiple antennas in both transmit and receive sides which enhances data capacity and reliability without extra power or bandwidth, and can perfectly solve this problem [3], [4].

For UWB-MIMO system, how to maintain acceptable isolation (no less than $10 \mathrm{~dB}$ ) between antenna elements through the wide operational band is a challenging task. Many researches has been reported recently [5-19]. Twoelement MIMO antenna system is reported in [5], without using common ground and separate the two elements about $0.37 \lambda_{0}$ from each other, no less than $15 \mathrm{~dB}$ isolation can be realized. Wideband neutralization line inserted between two monopoles to enhance the isolation between
3.1-5 GHz is proposed in [6]. Extruding T-shaped stub which changes the surface current in ground plane and increases the isolation is used in [7]. In [8], high isolation (no less than $10 \mathrm{~dB}$ ) is achieved by etching a slot on the center of the ground plane between two evolved meandering monopoles. Stage slots among antenna elements are used to reduce the coupling [9], and higher than $15.5 \mathrm{~dB}$ isolation can be realized through the UWB band. Polarization diversity is also an effective way in obtaining lower mutual coupling between antenna elements. In [10-18], antenna elements are placed perpendicular to each other to exploit polarization diversity and achieve high isolation. While in [19], polarization diversity between leaf-shaped slot antenna and similar shaped monopole is used to obtain good isolation in UWB high band (7.25-10.25 GHz).

In this paper, a four-element MIMO antenna system for UWB application is proposed. Polarization diversity of different kinds of antennas and specially designed decoupling structure make the mutual coupling between either elements lower than $-17 \mathrm{~dB}$ in the whole operational band $(3.1-10.6 \mathrm{GHz})$. The total dimension of the antenna system is $70 \times 41 \times 0.8 \mathrm{~mm}^{3}$, which is suitable for UWB portable devices.

\section{Antenna Design}

Figure 1 shows the geometry of the proposed MIMO antenna system. The system is built on a $0.8 \mathrm{~mm}$ thick FR4 substrate with relative permittivity 4.4 and loss tangent 0.02. All antenna elements are fed by tapered microstrip lines, which can improve the impedance matching in the UWB band. Two identical CPW-fed slot dipoles with L-shaped stubs and rectangular-shaped stubs for impedance matching are placed on the top side of the substrate (fed by port1 and port2), while two identical microstrip-fed planar monopoles (fed by port3 and port4) are set at the bottom of the substrate. The decoupling structure consists of two inverted L-shaped stubs and an inverted Z-shaped stub is also located on the top side of the substrate. We used the electromagnetic simulation software HFSS [20] to do the simulation. The parameters were changed one by a time, the optimized parameters are listed in Tab. 1. 


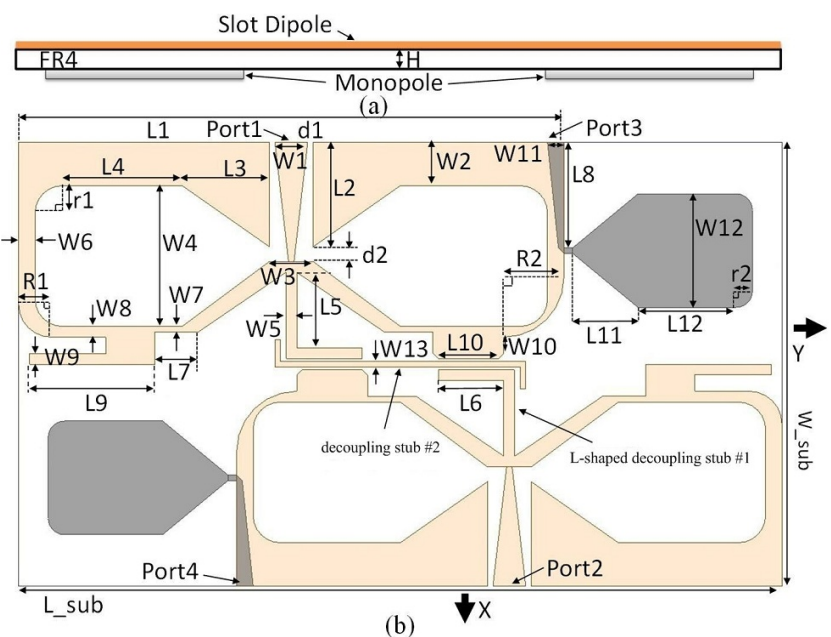

Fig. 1. Geometry of the 4-element MIMO antenna: (a) side view, (b) top view.

\begin{tabular}{|c|c|c|c|c|c|}
\hline Parameters & Value & Parameters & Value & Parameters & Value \\
\hline L_sub & 70 & L12 & 9 & W11 & 1.5 \\
\hline L1 & 50 & W_sub & 41 & W12 & 10.5 \\
\hline L2 & 10 & W1 & 3 & W13 & 0.5 \\
\hline L3 & 6.5 & W2 & 4 & d1 & 0.5 \\
\hline L4 & 13 & W3 & 4 & d2 & 1 \\
\hline L5 & 7 & W4 & 13 & r1 & 2.5 \\
\hline L6 & 6 & W5 & 1 & r2 & 1.5 \\
\hline L7 & 4 & W6 & 1.5 & R1 & 3.5 \\
\hline L8 & 9.75 & W7 & 0.5 & R2 & 5.5 \\
\hline L9 & 11.5 & W8 & 1 & H & 0.8 \\
\hline L10 & 5.5 & W9 & 1 & & \\
\hline L11 & 6 & W10 & 1.5 & & \\
\hline
\end{tabular}

Tab. 1. Antenna parameters (unit: $\mathrm{mm}$ ).

The round corners for all the four antennas are designed to provide smooth structure which is desirable for wide band performances.

The bandwidths of the slot dipoles are mainly decided by the length and the width of the antenna elements. When the total length of $(\mathrm{L} 4+\mathrm{L} 3+\mathrm{r} 1)$ is set as a constant, the lower frequency of Ant.1 or Ant.2 is fixed. The length used here is about one-fourth of wavelength at $3.1 \mathrm{GHz}$, which makes Ant.1 and Ant. 2 work as half wavelength slot dipoles. In Fig. 2(a), the decrease of L4 improves the impedance matching of the whole UWB band except for around $5 \mathrm{GHz}$. While in Fig. 2(b), the change of W4 mainly affects the impedance matching of lower than $7.5 \mathrm{GHz}$ band, increasing W4 decreases the amount of reflection coefficients. For the whole band, as shown in Fig. 2(c), the change of L3 has a weaker influence on impedance matching than the change of L4. In Fig. 2(d), considering the $-10 \mathrm{~dB}$ criterion, the increase of $\mathrm{W} 1$ mainly improves the impedance matching of the $6-9.6 \mathrm{GHz}$ band. While in Fig. 2(e), the increase of W3 mainly improves the impedance matching of the $5-6 \mathrm{GHz}$ band.

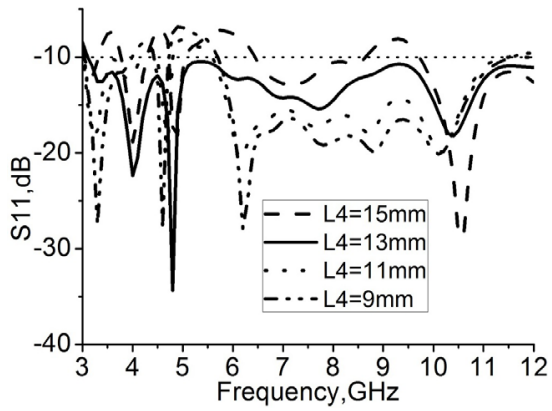

(a)

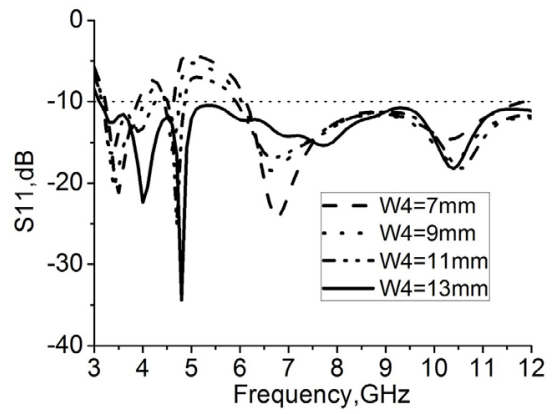

(b)

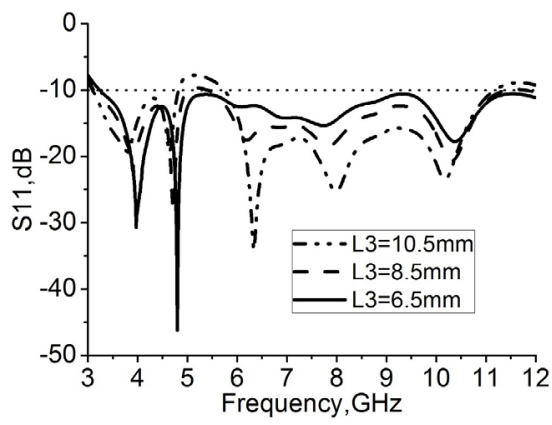

(c)

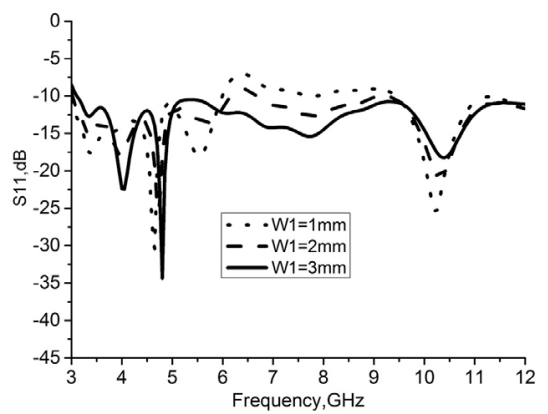

(d)

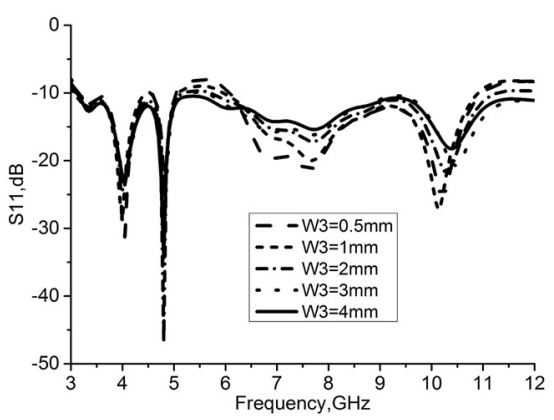

(e)

Fig. 2. Simulation results of S11 with the change of (a) L4, (b) W4, (c) L3, (d) W1 and (e) W3. 


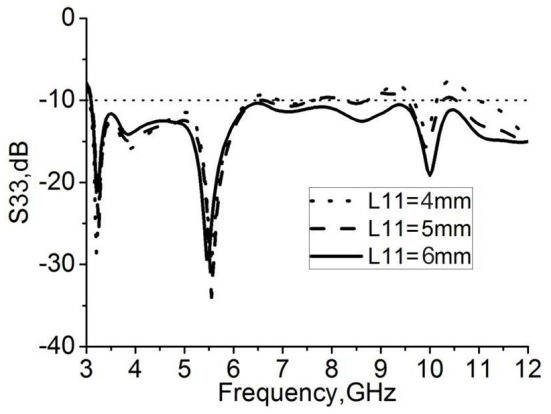

(a)

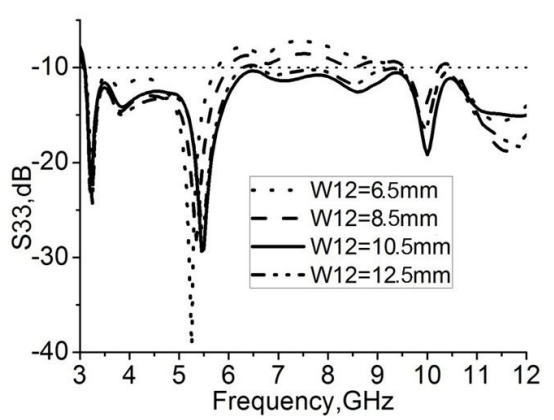

(b)

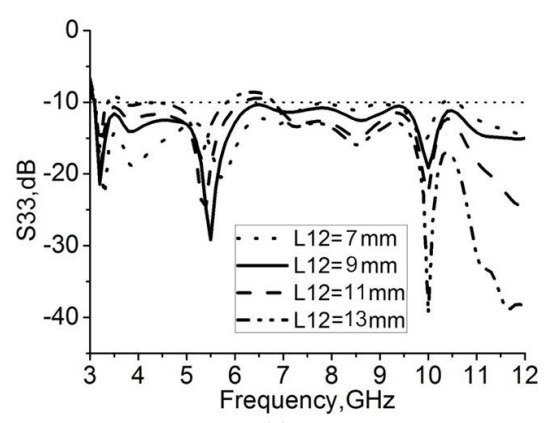

(c)

Fig. 3. Simulation results of S33 with the change of (a) L11, (b) W12 and (c) L12.

For Ant.3 and Ant.4, when (L11+L12+r2+L8) is fixed, which is about one-fourth wavelength at $3.1 \mathrm{GHz}$, the change of any of the components will not affect the lower frequency of the monopoles. As plotted in Fig. 3(a) and 3(b), the increase of L11 improves the impedance matching of higher than $5 \mathrm{GHz}$ band. The change of W12 affects the higher than $6 \mathrm{GHz}$ band of the antennas, while the change of L12 has an influence on the whole operation band (Fig. 3(c)).

The functions of the attached L-shaped and rectangular-shaped stubs, and the decoupling structures can be explained by designing the UWB-MIMO system in four evolution steps which are plotted in Fig. 4. Since when the overall size is decided, the monopoles can maintain well matched through the whole band, we mainly focused on impedance matching of the slot dipoles. While high isolation can be obtained by polarization diversity between different kinds of antennas, only the isolation between the monopoles cannot meet the $10 \mathrm{~dB}$ criterion through the whole band. The decoupling structures are designed to solve this problem.
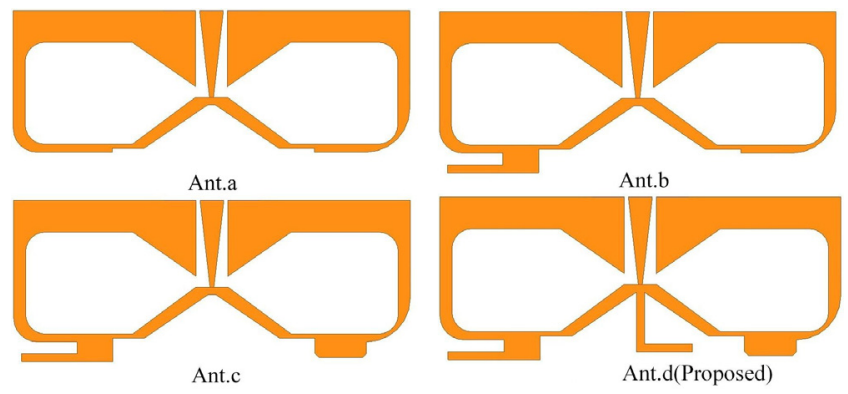

Fig. 4. Design steps (Ant.a-d).

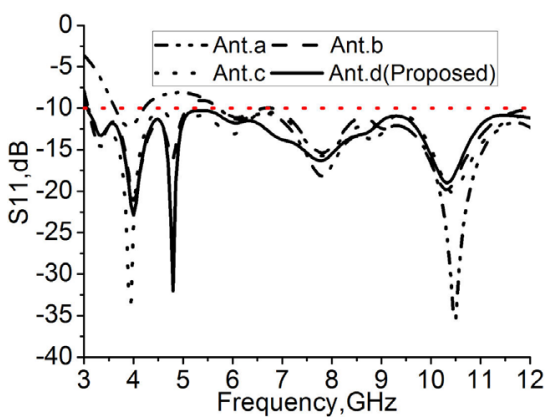

(a)

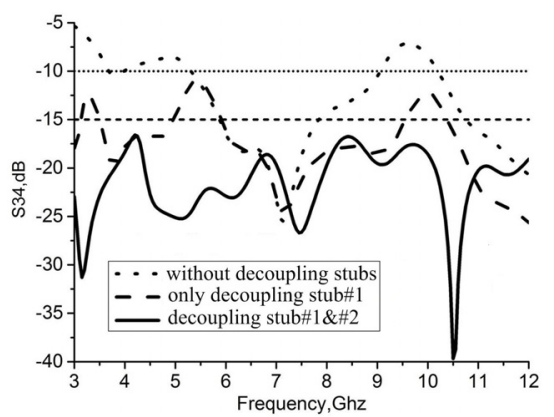

(b)

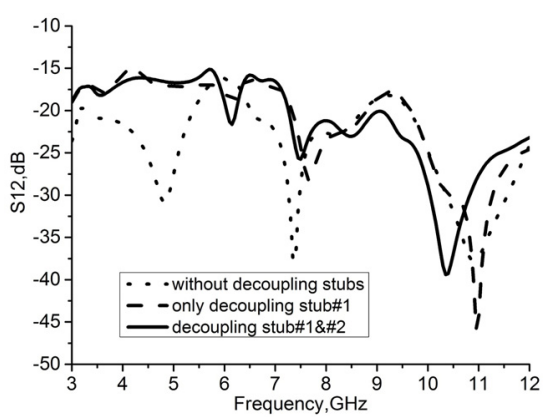

(c)

Fig. 5. Simulated S parameters: (a) S11 in four evolution steps, (b) change of S34 with the decoupling structures, (c) change of S12 with the decoupling structures.

As can be seen in Fig. 5(a), for Ant.a, at frequencies lower than $5.7 \mathrm{GHz}$, the antenna is not well matched. By adding an impedance matching L-shaped stub (Ant.b), impedance matching can be improved except for frequency from 5.1 to $5.7 \mathrm{GHz}$. One rectangular shaped stub is added to further fine tune the antenna. For Ant.c and Ant.d, they both can cover the whole UWB band under $-10 \mathrm{~dB}$ impedance matching criterion. The function of the decoupling structures in isolation improvement is plotted in Fig. 5(b). 

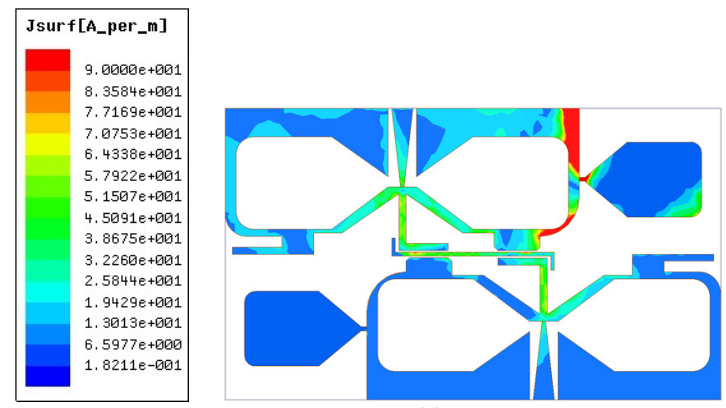

(a)

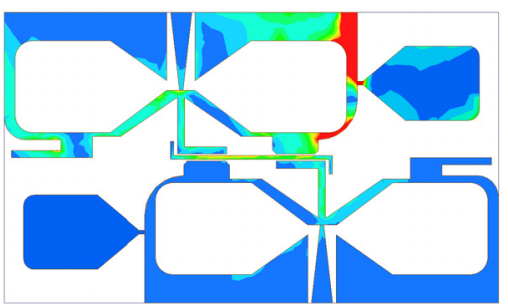

(b)

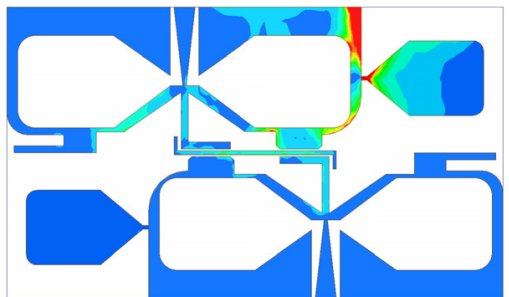

(c)

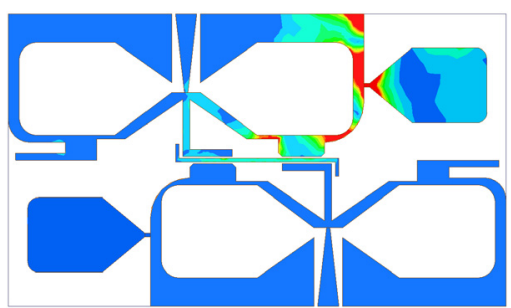

(d)

Fig. 6. Surface current distributions of the proposed UWB MIMO antenna when element\#3 is fed at (a) 3.5, (b) 4, (c) 5.8 , and (d) $8 \mathrm{GHz}$.

With only a pair of inverted L-shaped stubs (decoupling stub\#1), the isolation between the monopoles can be improved to higher than $10 \mathrm{~dB}$. By adding an inverted Z-shaped stub, LC resonances structure between two kinds of stubs occurs, and the isolation can be further enhanced to higher than $17 \mathrm{~dB}$. In Fig. 5(c), we can see with and without the decoupling stubs, the isolation between Ant.1 and Ant. 2 is higher than $15 \mathrm{~dB}$. The decoupling structures have no positive impact on the isolation except for around $5.8 \mathrm{GHz}$ and higher than $8 \mathrm{GHz}$, but the effect is still weak compared to the influence on S34.

Figure 6 depicts the surface current distributions of the proposed UWB MIMO antenna at 3.5, 4, 5.8, and $8 \mathrm{GHz}$ to further investigate how the pair of inverted L-shaped stubs and inverted Z-shaped stub increase the isolation. For monopoles, the metal contours of the slot-dipoles are used as their ground, when surface current flows on the ground, strong coupling occurs. In Fig. 6 , it can be seen that through the UWB band, when Ant.3 is fed, the surface current is mainly trapped by the decoupling structures, so the mutual interference between the monopoles is alleviated.

\section{Results and Discussion}

Figure 7 shows the top and bottom pictures of the fabricated antenna system. The proposed antenna system was measured by using Agilent $85058 \mathrm{E}$ vector network analyzer.

As shown in Fig. 8(a), both the simulated and measured bandwidths can cover the UWB band, for the sake of clarity, we only put the results of two antennas here. The measured isolation between antennas is higher than $17 \mathrm{~dB}$ (Fig. 8(b)). For Ant.1 with Ant.2, since the radiation characteristics for the slot dipoles change with frequency, the isolation changes with frequency, too. Especially for frequencies between $6.5-8.5 \mathrm{GHz}$, the mutual coupling becomes relatively strong. For Ant. 1 with Ant.3 or Ant. 1 with

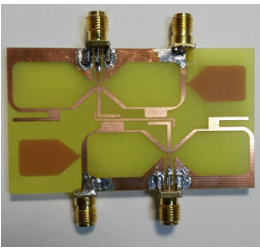

(a)

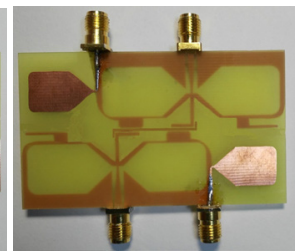

(b)
Fig. 7. Photograph of the fabricated antenna system: (a) top view and (b) bottom view.

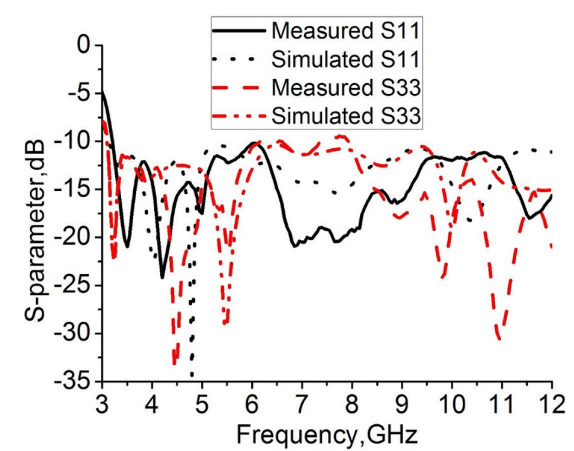

(a)

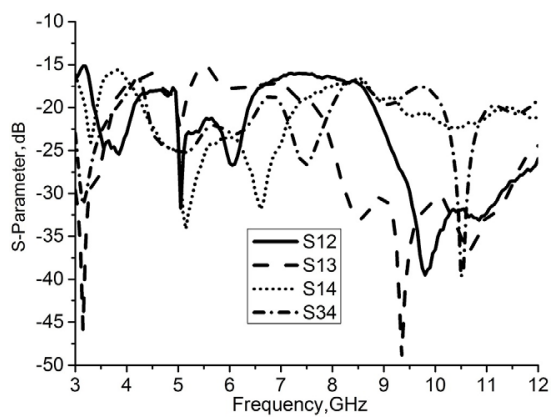

(b)

Fig. 8. (a) Reflection coefficients of the MIMO antenna system. (b) Measured isolation between MIMO antenna elements. 


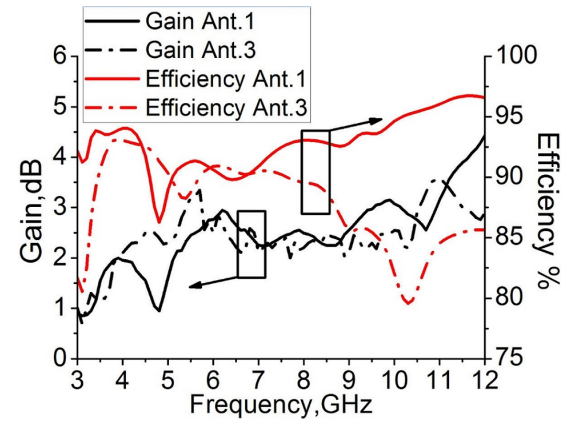

Fig. 9. Gain and radiation efficiencies for the proposed MIMO antenna system.

Ant.4, high isolation occurs because of the polarization diversity. Meanwhile, since the radiation characteristics for both kinds of antennas change with frequency, the isolation changes with frequency, too. Generally, if strong radiation of two antennas is pointing to each other, the mutual coupling will be strong. For Ant.3 with Ant.4, the change of electromagnetic property of the decoupling structures with frequency causes the changes of mutual coupling between the two antennas.

The measured gains and simulated efficiencies against frequency are presented in Fig. 9. The measured gain varies from 1.4-3.9 dBi for the slot dipole and 1-3.7 dBi for the monopole. The simulated efficiencies are no less than $80 \%$ for both kinds of antennas.

Figure 10 shows the radiation pattern of Ant.1 and Ant. 3 at $5 \mathrm{GHz}$. Beside polarization diversity, pattern diversity can also be found from the simulated $3 \mathrm{D}$ radiation pattern. When Ant.1 is excited, radiation nulls are along the Y-axis, while for Ant.3, the radiation nulls are along the $\mathrm{X}$-axis. The strong radiation between two antenna elements avoids pointing to each other. But for Ant.3 and Ant.4, the strong radiation is directed to each other. This explains why the isolation between Ant. 3 and Ant.4 is the lowest. Similar performances between antenna elements can be found at other frequencies.

The measured and simulated $2 \mathrm{D}$ radiation patterns for Ant. 1 and Ant. 3 at $5 \mathrm{GHz}$ and $8 \mathrm{GHz}$ are plotted in Fig. 11 and Fig. 12. The radiation patterns are measured when the target antenna is excited and other three antennas are terminated with the $50 \mathrm{ohm}$ load. Differences are mainly caused by the fabrication error.

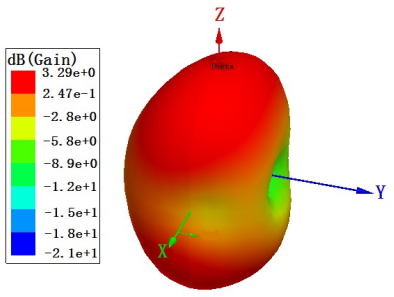

(a)

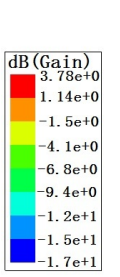

(b)

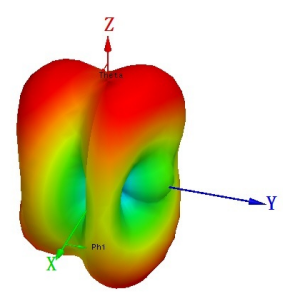

Fig. 10. Simulated 3D radiation pattern of (a) Ant.1 and (b) Ant. 3 at $5 \mathrm{GHz}$.

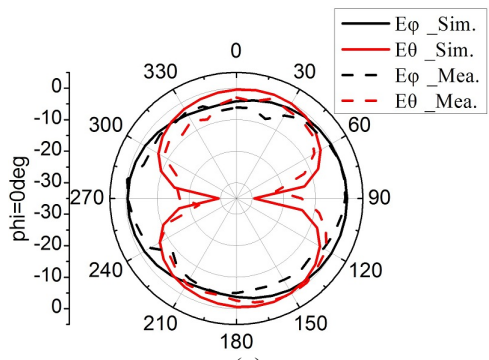

(a)

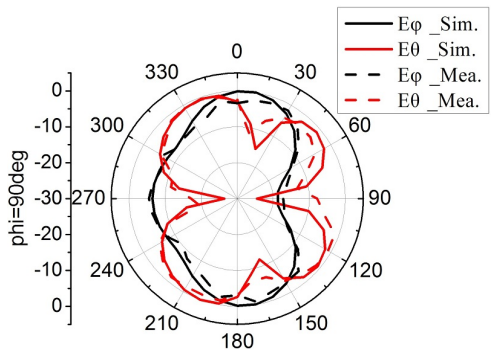

(b)

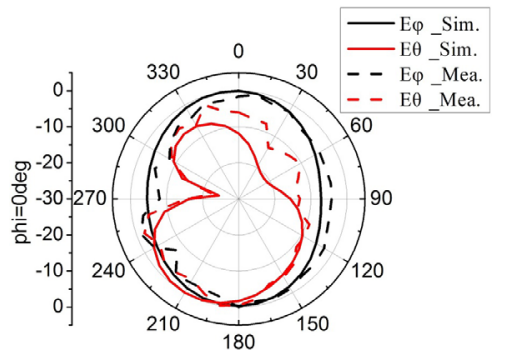

(c)

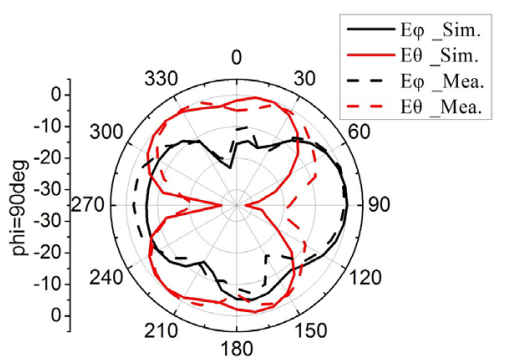

(d)

Fig. 11. Simulated and measured radiation patterns of Ant.1 and Ant. 3 at 5 GHz: (a) Ant. 1 xz-plane, (b) Ant. 1 yzplane, (c) Ant. 3 xz-plane, (d) Ant.3 yz-plane.

In Fig. 13, the measured envelope correlation coefficients were calculated by using the following equation [21] and the results are lower than 0.015, which shows good isolation between antenna elements.

$$
\rho_{i j}=\frac{\left|\iint_{4 \pi}\left(\Gamma \cdot E_{\theta j}^{*}+E_{\varphi i}(\Omega) \cdot E_{\varphi j}^{*}\right) \mathrm{d} \Omega\right|^{2}}{\iint_{4 \pi}\left(\Gamma \cdot G_{\theta i}(\Omega)+G_{\varphi i}(\Omega)\right) \mathrm{d} \Omega \cdot \iint_{4 \pi}\left(\Gamma \cdot G_{\theta j}(\Omega)+G_{\varphi j}(\Omega)\right) \mathrm{d} \Omega}
$$

where $\mathrm{G}_{\theta i}(\Omega)=E_{\theta i}(\Omega) \cdot E_{\theta i}^{*}(\Omega)$ and $\mathrm{G}_{\theta j}(\Omega)=E_{\theta j}(\Omega) \cdot E_{\theta j}^{*}(\Omega)$, $\Gamma$ is the reflection coefficient. $E_{\theta}$ and $E_{\varphi}$ are the $\theta$ and $\varphi$ polarized realized active electric field patterns of the antennas. $G_{\theta}$ and $G_{\varphi}$ are the $\theta$ and $\varphi$ polarized components of the antennas' realized active power gain patterns and $\Omega$ is the solid angle. 


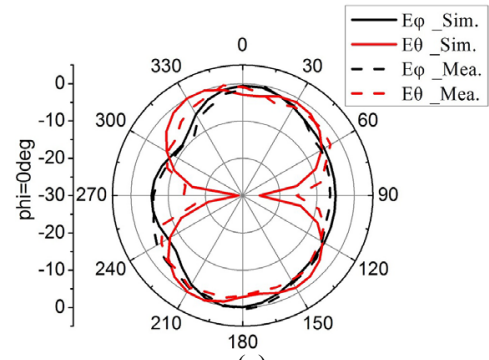

(a)

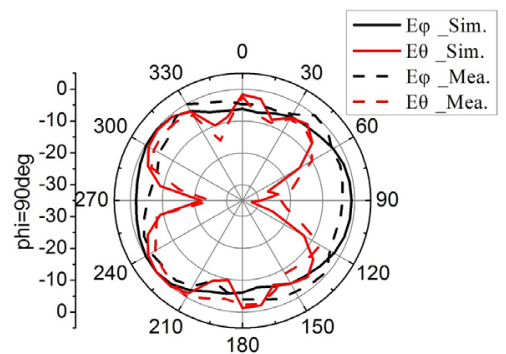

(b)

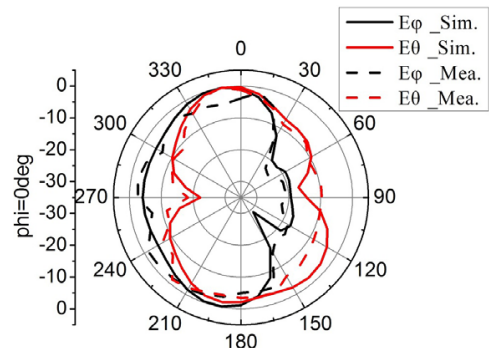

(c)

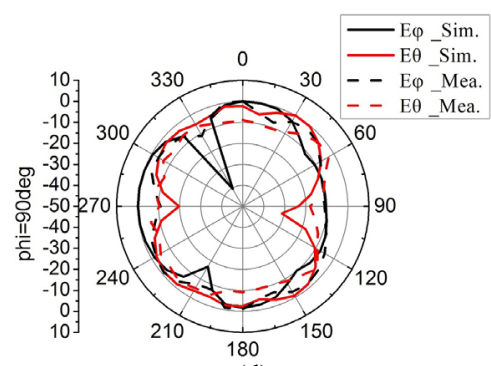

(d)

Fig. 12. Simulated and measured radiation patterns of Ant.1 and Ant. 3 at $8 \mathrm{GHz}$ : (a) Ant. 1 xz-plane, (b) Ant.1 yz-plane, (c) Ant. 3 xz-plane, (d) Ant.3 yz-plane.

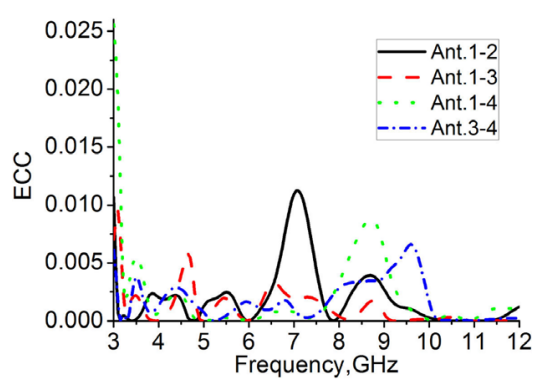

Fig. 13. Envelope Correlation Coefficients.

Diversity Gain (DG), Total Active Reflection Coefficient (TARC) and Channel Capacity Loss (CCL) can be calculated to evaluate the MIMO behavior of the proposed antenna system together with ECC. By using equation mentioned in [22], the DGs of all antennas are larger than
$9.95 \mathrm{~dB}$. The TARC of antenna\#1 and antenna\#3 is calculated at each random phase between $0^{\circ}$ and $180^{\circ}$ according to [23]. However, only phases $0^{\circ}$ and $180^{\circ}$ are plotted in Fig. 14. For both types of antennas, they still can cover the whole UWB band. The measured CCL is calculated by using formula given in [17], and the result is shown in Fig. 15. It can be observed that the result satisfies the acceptable limits of $\mathrm{CCL}<0.4 \mathrm{bits} / \mathrm{s} / \mathrm{Hz}$ through the whole UWB band.

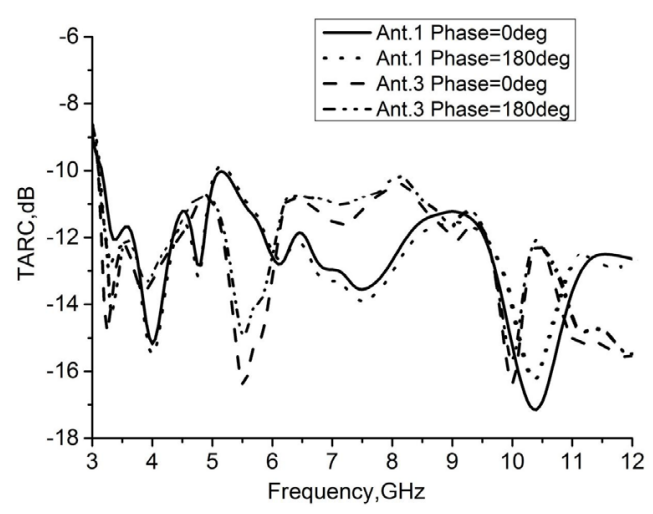

Fig. 14. Total active reflection coefficients (TARC).

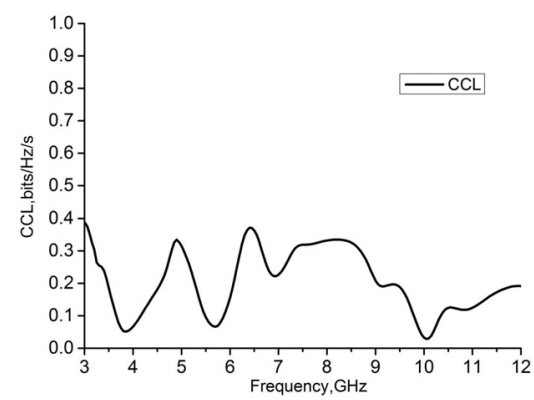

Fig. 15. The measured channel capacity loss of the proposed UWB MIMO antenna.

\begin{tabular}{|c|c|c|c|c|}
\hline Designs & Size $\left(\mathrm{mm}^{2}\right)$ & Band $(\mathrm{GHz})$ & Isolation $(\mathrm{dB})$ & ECC \\
\hline$[9]$ & $44 \times 44$ & $2.95-10.8$ & 15.5 & $<0.04$ \\
\hline$[11]$ & $50 \times 39.8$ & $\begin{array}{c}2.7-5.1, \\
5.9-12\end{array}$ & 17 & $<0.01$ \\
\hline$[13]$ & $44 \times 44$ & $3.1-11$ & 16 & $<0.1$ \\
\hline$[16]$ & $38 \times 38$ & $3-15$ & 14 & $<0.2$ \\
\hline$[17]$ & $40 \times 40$ & $3.1-11$ & 20 & $<0.004$ \\
\hline$[19]$ & $42.5 \times 54$ & $7.25-10.5$ & 15 & $<0.15$ \\
\hline Proposed & $70 \times 41$ & $3.1-12$ & 17 & $<0.012$ \\
\hline
\end{tabular}

Tab. 2. Comparisons among recent published 4-element UWB-MIMO antenna systems and this work.

The comparisons among the recently published 4-element UWB-MIMO antenna systems and this design are listed in Tab. 2. It can be observed that our design has a relatively compact size, and high isolation, which is important for UWB-MIMO applications.

\section{Conclusion}

In this paper, a novel compact four element MIMO antenna system was proposed. High isolation among 
antenna elements through the UWB band was realized in three steps: 1) Using polarization diversity between different kinds of antenna elements. 2) Adding a pair of inverted L-shaped decoupling stubs. 3) Introduce an inverted Zshaped decoupling stub between L-shaped stubs to form LC resonances structure. The results of S-parameters, gain, radiation characteristics and MIMO performances like envelope correlation coefficients, TARC all show the proposed antenna system a competitive candidate for UWBMIMO applications.

\section{Acknowledgments}

This work was supported by the Priority Academic Program Development of Jiangsu Higher Education Institutions (PAPD) and Jiangsu Innovation \& Entrepreneurship Group Talents Plan.

\section{References}

[1] BEKASIEWICZ, A., KOZIEL, S. Compact UWB monopole antenna for internet of things applications. Electronics Letters, 2016, vol. 52, no. 7, p. 492-494. DOI: 10.1049/el.2015.4432

[2] LUO, C. M., HONG, J. S., ZHONG, L. L. Isolation enhancement of a very compact UWB-MIMO slot antenna with two defected ground structures. IEEE Antennas and Wireless Propagation Letters, 2015, vol. 14, p. 1766-1769. DOI: 10.1109/LAWP.2015.2423318.

[3] YANG, L. S., FANG, J. P., LI, T. Compact dual-band MIMO antenna system for mobile handset application. IEICE Transactions on Communications, 2015, vol. E98.B, p. 2463-2469. DOI: 10.1587/transcom.E98.B.2463.

[4] CHANDEL, R., GAUTAM, A. K., RAMBABU, K. Tapered fed compact UWB MIMO-diversity antenna with dual band-notched characteristics. IEEE Transactions on Antennas and Propagation, 2018, vol. 66, no. 4, p. 1677-1684. DOI: 10.1109/TAP.2018.2803134

[5] IBRAHIM, A. A., ABDAlla, M. A., HU, Z. R. Design of a compact MIMO antenna with asymmetric coplannar strip-fed for UWB applications. Microwave and Optical Technology Letters, 2017, vol. 59, no. 1, p. 31-36. DOI: 10.1002/mop.30208

[6] ZHANG, S., PEDERSEN, G. F. Mutual coupling reduction for UWB MIMO antennas with a wideband neutralization line. IEEE Antennas and Wireless Propagation Letters, 2016, vol. 15, p. 166-169. DOI: 10.1109/LAWP.2015.2435992

[7] CHANDEL, R., GAUTAM, A. K. Compact MIMO/diversity slot antenna for UWB applications with band-notched Characteristic. Electronics Letters, 2016, vol. 52, no. 5, p. 336-338. DOI: 10.1049/el.2015.3889

[8] DENG, J. Y., GUO, L. X., LIU., X. L. An ultrawideband MIMO antenna with a high isolation. IEEE Antennas and Wireless Propagation Letters, 2016, vol. 15, p. 182-185. DOI: 10.1109/LAWP.2015.2437713

[9] LIU, Y. Y., TU, Z. H. Compact differential band-notched steppedslot UWB-MIMO antenna with common-mode suppression. IEEE Antennas and Wireless Propagation Letters, 2017, vol. 16, p. 593-596. DOI: 10.1109/LAWP.2016.2592179
[10] REN, J., HU, W., YIN, Y. Z., et al. Compact printed MIMO antenna for UWB applications. IEEE Antennas and Wireless Propagation Letters, 2014, vol. 13, p. 1517-1520. DOI: 10.1109/LAWP.2014.2343454

[11] KHAN, M. S., CAPOBIANCO, A. D., ASIF, S., et al. Compact $4 \times 4$ UWB-MIMO antenna with WLAN band rejected operation. Electronics Letters, 2015, vol. 51, no. 14, p. 1048-1050. DOI: 10.1049/el.2015.1252

[12] KIEM, N. K., PHUONG, H. N. B., CHIEN, D. N. Design of compact $4 \times 4$ UWB-MIMO antenna with WLAN band rejection. International Journal of Antennas and Propagation, 2014, p. 1-11. DOI: $10.1155 / 2014 / 539094$

[13] GURJAR, R., UPADHYAY, D. K., KANAUJIA, B. K. Compact four-element 8-shaped self-affine fractal UWB MIMO antenna. In 2018 3rd International Conference on Microwave and Photonics (ICMAP). Dhanbad (India), 2018, p. 1-2. DOI: 10.1109/ICMAP.2018.8354571

[14] AQUIL, J., SARKAR, D., SRIVASTAVA, K. V. A quasi selfcomplementary UWB MIMO antenna having WLAN-band notched characteristics. In 2017 IEEE Applied Electromagnetics Conference (AEMC)., Aurangabad (India), 2017, p. 1-2. DOI: 10.1109/AEMC.2017.8325722

[15] REDDY, P. N. K., ANURADHA, S. A compact four element UWB MIMO antenna. In 2017 International Conference on Trends in Electronics and Informatics (ICEI). Tirunelveli (India), 2017, p. 949-952. DOI: 10.1109/ICOEI.2017.8300847

[16] SIPAL, D., ABEGAONKAR, M. P., KOUL, S. K. Easily extendable compact planar UWB MIMO antenna array. IEEE Antennas and Wireless Propagation Letters, 2017, vol. 16, p. 2328-2331. DOI: 10.1109/LAWP.2017.2717496

[17] ALI, W. A. E., IBRAHIM, A. A. A compact double-sided MIMO antenna with an improved isolation for UWB applications. International Journal of Electronics and Communications, 2017, vol. 82, p. 7-13. DOI: 10.1016/j.aeue.2017.07.031

[18] IBRAHIM, A. A., MACHAC, J., SHUBAIR, R. M. Compact UWB MIMO antenna with pattern diversity and band rejection characteristics. Microwave and Optical Technology Letters, 2017, vol. 59, no. 6, p. 1460-1464. DOI: 10.1002/mop.30564

[19] MAEDA, S., YAMAMOTO, M., NOJIMA, T. A wideband 4-port MIMO antenna using leaf-shaped bowtie radiating elements (in Japanese). IEICE Technical Report, 2015, vol. 114, no. 245, p. 886-895. ISSN: 0913-5685.

[20] ANSYS HFSS: High Frequency Simulator Based on the Finite Element Method, Version 15, ANSYS Corp.

[21] VAUGHAN, R. G., ANDERSEN J. B. Antenna diversity in mobile communications. IEEE Transactions on Vehicular Technology, 1987, vol. 36, no. 4, p. 149-172. DOI: 10.1109/TVT.1987.24115

[22] IQBAL, A., SARAEREH, O. A., AHMAD, A. W., et al. Mutual coupling reduction using F-shaped stubs in UWB-MIMO antenna. IEEE Access, 2018, vol. 6, p. 2755-2759. DOI: 10.1109/ ACCESS.2017.2785232

[23] ABDALLA, M. A., IBRAHIM, A. A. Simple mu-negative half mode CRLH antenna configuration for MIMO applications. Radioengineering, 2017, vol. 26, no. 1, p. 45-50. DOI: $10.13164 /$ re. 2017.0045

\section{About the Authors ...}

Lingsheng YANG (corresponding author) was born in Jiangsu Province, China. He received his B.S. degree in the 
Department of Communication Engineering, Nanjing University of Science \& Technology, China, in 2001, and the M.S. and Ph.D. degrees in the Faculty of Information Science and Electrical Engineering, Kyushu University, Japan, in 2009 and 2012, respectively. His research interests include antenna theory and design, MIMO, EMC and lightning detection.

Ming XU was born in Shandong Province, China. She received her B.S. degrees in the Institute of Physics and Electronic Information, Dezhou University, China in 2016. Now, she is working towards master degree at NanJing
University of Information Science \& Technology, China. Her research interests include MIMO antenna system design and antenna for mobile terminals.

Chun LI was born in Jiangsu Province, China. He received his B.S. degrees in the Department of Electrical Engineering, NanJing University of Information Science \& Technology, China in 2015. Now, he is working towards master degree at NanJing University of Information Science \& Technology, China. His research interests include MIMO antenna system design and antenna for mobile terminals. 